\title{
Structure, function and membrane interactions of plant annexins: an update
}

\author{
Dorota Konopka-Postupolska ${ }^{1}$, Greg Clark ${ }^{2}$ \& Andreas Hofmann ${ }^{3,4^{*}}$
}

\author{
${ }^{1}$ Institute of Biochemistry and Biophysics, Polish Academy of Sciences, Warsaw, Poland \\ ${ }^{2}$ Section of Biological Sciences, Molecular Cell and Developmental Biology, University of Texas at \\ Austin, TX, USA \\ ${ }^{3}$ Structural Chemistry Program, Eskitis Institute for Cell and Molecular Therapies, Griffith \\ University, Nathan, Qld, Australia \\ ${ }^{4}$ Department of Veterinary Science, The University of Melbourne, Victoria, Australia
}

*Corresponding author: $\quad$ N75 Don Young Road

Nathan, Qld 4111, Australia

Telephone/Facsimile: +61-7-3735-4425

Email: a.hofmann@griffith.edu.au

Manuscript: p_10.doc, Plant Science

Word count: 11883

Keywords: membrane resealing, oxidative stress, phosphorylation, polar growth 


\begin{abstract}
Knowledge accumulated over the past 15 years on plant annexins clearly indicates that this disparate group of proteins builds on the common annexin function of membrane association, but possesses divergent molecular mechanisms. Functionally, the current literature agrees on a key role of plant annexins in stress response processes such as wound healing and drought tolerance. This is contrasted by only few established details of the molecular level mechanisms that are driving these activities.

In this review, we appraise the current knowledge of plant annexin molecular, functional and structural properties with a special emphasis on topics of less coverage in recent past overviews. In particular, plant annexin post-translational modification, roles in polar growth and membrane stabilisation processes are discussed.
\end{abstract}

\title{
Introduction
}

Genome sequencing revealed that annexins in plants comprise a multigene family with several members, eight in Arabidopsis thaliana [1] and nine in Oryza sativa [2]. Many annexins from other plant species have been reported to date, albeit a systematic mapping of annexins in most plants is still lacking. The defining criterion of annexins is their highly conserved fold which is also observed in plant annexins. It consists of a four-fold repeat (I-IV) of a 70 amino acid sequence that constitutes the C-terminal (core) domain (see Figure 1). Each repeat forms the characteristic fivehelix (A-E) bundle with membrane binding sites situated in the AB and DE loops. Canonical calcium binding occurs in type II or type III binding sites. The former type is established through the endonexin sequence G-X-G-T-\{38-40\}- D/E, where the G-X-G-T motif is found in the AB loops, and the bidentate acidic side chain is located at the C-terminal end of helix $\mathrm{D}$ in the same repeat. The N-terminal domain is situated at the opposite side of the molecule and typically not facing the membrane. It can vary in length from 5-50 amino acids, and may associate with the core domain as well as confer allosteric regulation [3].

Previous overviews on plant annexins have summarised the current knowledge protein expression in plants, biochemical and structural characterisation and putative physiological roles [4-7]. This review attempts an update on some less covered aspects of plant annexins, namely posttranslational modification and a role in controlling differential growth. Furthermore, a new link between the recurring phenomenological observation of plant annexin roles in stress with underlying molecular mechanisms may be established through the recent discovery of vertebrate annexin roles in plasma membrane re-sealing. Lastly, an appraisal of annexin membrane interactions is conducted.

\section{Molecular structure}

Experimental structural information is available in the form of crystal structures of bell pepper annexin 24 (Ca32) [8], cotton annexin $\operatorname{Anx}(\mathrm{Gh}) 1$ [9, 10] and Arabidopsis Anx(At)1 [11]. The main structural features separating plant from vertebrate annexins include two dysfunctional canonical calcium binding sites, direct interactions of side chain residues on the convex side for membrane binding, and the propensity for oligomer formation in case of the plant proteins.

Based on the primary structure, it was hypothesised early on that plant annexins would only be able to bind calcium ions in a canonical fashion in repeats I and IV [12]; these predictions were later confirmed by the crystal structure of calcium bound $\operatorname{Anx}(\mathrm{Gh}) 1$ [10] which remains the only structure of a calcium-bound plant annexin to date. In repeat II, a histidine residue in place of the required acidic bidentate side chain renders the type II calcium binding site dysfunctional. The 
endonexin sequence is absent in repeat III, and despite the presence of the bidentate acidic residue, the conformation of side chains in the IIIAB loop are unfavourable for calcium binding.

Plant annexins possess several basic and hydrophobic residues on their convex side that are found in exposed positions in crystal structures. These residues provide enable calcium-independent membrane interactions, which has experimentally been corroborated by a mutagenesis study [13].

A tryptophan switch in repeat I, reminiscent of that observed in the third repeat of AnxA5, is apparent from the comparison of crystal structures of plant annexins. The highly conserved tryptophan residue in the IAB loop of plant annexins adopts a several different conformations, including a loop-in (harboured within an intra-molecular position), half-way (in membrane binding position) and loop-out (involved in intermolecular contacts). This loop switch is not triggered by calcium (Hofmann, unpublished results), and may serve as a versatile inter-molecular contact. Interestingly, the absence of this tryptophan residue results in a diminished calcium-dependent membrane binding [13].

The conserved tryptophan residue in repeat I may play a role in the tendency of plant annexins to exist as oligomers in solution [14]. In the loop-out conformation, this tryptophan residue is bound in a hydrophobic pocket presented by the AB and DE loops of the third repeat (Phe-229 and Tyr-190; Anx(Gh)1 numbering). When comparing the crystal lattices of known plant annexin structures, other contacts include hydrogen bonding and salt bridges involving the side-chain pairs Gln-123 Tyr-156, Glu-135 - Arg-196, Arg-146 - Glu-187 (Anx(Gh)1 numbering), bringing helices IIC, D and $\mathrm{E}$ of one molecule in proximity to helix IIIB of another molecule. Interestingly, all of those residues involved in the intermolecular contacts mentioned are conserved in many plant annexins. Small-angle X-ray scattering results indicate the formation of prolate oligomers of bell pepper annexin 24(Ca32) of high molecular mass (Hofmann \& Pedersen, unpublished results).

Some plant annexins have a peroxidase activity that was proposed to utilise heme in the electron transfer process. The reason for this hypothesis came from analysis of the amino acid sequence of the plant annexins which possess a conserved histidine residue within a sequence that seemed similar to a sequence observed in plant peroxidases [15]. A caveat should be applied to this and many similar predictions where structural models are proposed exclusively based on amino acid sequence data. The fact that there is amino acid sequence similarity in two different proteins does not necessarily mean that there is three-dimensional structural resemblance. Unfortunately, there is still a lack in use and analysis of reliable three-dimensional structures (or models) in many such predictions.

To date, there is no experimental evidence for heme binding by plant annexins, and based on the structural data available, heme binding by plant annexins does not seem feasible. Firstly, the histidine residue in question (His-40, $\operatorname{Anx}(\mathrm{Gh}) 1$ numbering) is located near the C-terminal end of helix IB and serves as an anchor point for the association of the N-terminal domain with the Cterminal core through hydrogen bonding with the backbone carbonyl group of residue 13 (Anx(Gh)1 numbering). This prevents the histidine side chain from further intermolecular contacts. Secondly, no suitable pocket on the surface of the annexin molecule in this area can be identified that may be able to accommodate the large porphyrin ring. And lastly, in a test for heme binding, comparing the UV/Vis spectra of myoglobin, Anx(Gh)1 wild-type and Anx(Gh)1-H40A had no shift of the Soret band of heme in the presence of the annexin proteins (Osman \& Hofmann, unpublished data) [16].

Structurally, however, His-40 is a key residue providing stability through anchoring of the Nterminal domain to the core as observed in all plant annexin crystal structures so far. This is an agreement with findings from an $\mathrm{Anx}(\mathrm{At}) 1-\mathrm{H} 40 \mathrm{~A}$ mutant where the overall secondary structure of the protein has been found to be significantly affected [17].

\section{Post-translational modification}




\section{Knowledge from vertebrate annexins}

Post-translational modifications may have an enormous impact on the structure of a protein, and subsequently on its function, and provide functionalities or interactions that will lead to translocation or protein-protein interactions. The $\mathrm{N}$-terminal domain in vertebrate annexins, is a main source of structural and functional diversity when comparing different members of this protein family. It can undergo several post-translational modifications, including phosphorylation [18], transglutamination [19], myristoylation [20, 21] and S-glutathionylation [22].

Phosphorylation on serine, threonine and/or tyrosine residues regulate cellular function and the response of plant cells to environmental changes. This post-translational modification is a consequence of the coordinated action of kinases (about 1500 and 1003 in rice and Arabidopsis genome, respectively) and phosphatases (about 132 and 116 in rice and Arabidopsis genome, respectively) and results in the direct or indirect alteration of the activity of the target protein, such as e.g. interaction with 14-3-3 proteins.

Structurally, phosphorylation of the annexin N-terminal tail can affect its attachment to the Cterminal core [23, 24], resulting in altered susceptibility towards proteolysis [25]. This, in turn, modifies calcium sensitivity and phospholipid binding [23, 24, 26, 27] e.g. by precluding the faceto-face annexin self-association required to aggregate membrane structures [28]. Physiologically, this may indicate a phosphorylation-dependent regulation of vesicle trafficking by annexins, albeit dependent on the annexin, and on the cell types and pathways that are regulated by certain kinase. Annexins are substrates of different kinases that phosphorylate tyrosine (non-receptor kinase like Src, receptor kinases binding EGF, PDGF, insulin), as well as serine/threonine residues, e.g. calcium-dependent protein kinase C (PKC), c-AMP dependent protein kinase A (PKA), mitogen activated kinases MAPK, and casein kinase CKII. It was hypothesized that annexins could be involved in receptor-triggered endocytosis upon phosphorylation by tyrosine kinases [29] and vesicle aggregation after PKC [30-32]. However, different annexins were found to exert opposite effects on vesicle aggregation; while phosphorylated AnxA1 or AnxA2 inhibit aggregation, phosphorylated AnxA7 enhance this process.

Phosphorylation can also regulate annexin translocation between different cellular compartments, and a particular annexin may target different locations, depending on the site being phosphorylated. For instance, phosphorylation of AnxA2 Tyr-23 by Src tyrosine kinase results in translocation to the plasma membrane [33], where it inhibits actin bundling [34]. This effect on cytoskeletal rearrangement ultimately results in changes to cell morphology as well as cell motility [35, 36]. In contrast, Ser-25 phosphorylation mediated by protein kinase $C$ induces the active entry of AnxA2 into the nucleus $[37,38]$. In this context, annexins may be part of a feedback mechanism, since AnxA1 is both a substrate and a modulator of proximal elements of some MAPK signaling pathways in vitro [39, 40]. Although nucleotide binding (and low level phosphodiesterase) activity of plant annexins has been reported, there still exists a lack of sufficient molecular detail and the biological significance remains unclear. Structurally, the observed phosphodiesterase activity may be an "accidental" side product in the milieu of the metal binding sites and the unique protein surface on the convex side of plant annexins.

Considering that the N-terminal domain of annexins is frequently involved in interactions with other proteins, phosphorylation in this region is likely to constitute a component of signal transduction that is structurally achieved by a conformational change in the secondary structure of this region of the molecule $[41,42]$. For instance, the phosphorylation of Ser-5 of AnxA1 mediated by TRMP7 kinase prevents the formation of $\alpha$-helical secondary structure in the N-terminal domain and thus weakens the interactions with the annexin-binding protein S100A11 [43, 44].

In addition to the N-terminal domain, the C-terminal globular core domain of annexins is also phosphorylated (e.g. His-246 or His-293 of AnxA1 [45]; Tyr-216 of AnxA1 [46]) but the significance of this phosphorylation is less understood. 
The most important conclusion learned from vertebrate annexin phosphorylation is that multiple sites can be phosphorylated by different kinases, resulting in diverse effects. This enables a precise fine-tuning of the response of a particular annexin to particular extracellular and intracellular signals. It also ideally positions annexins within cellular pathways to integrate and consolidate information from different signaling pathways.

\section{Phosphorylation of plant annexins}

The $34 \mathrm{kDa}$ annexin isolated from cotton fibers consists of three isoforms that differ in pI, ranging from 6.1 to 6.5 [47]. Similarly, annexin isolated from Mimosa pudica seedlings [48], as well as Anx(At)1 present in root microsomal fraction [49], have two isoforms. These observations indicate that native plant annexins are indeed phosphorylated; however, a systematic investigation of plant annexin phosphorylation remains to be conducted.

While it cannot be excluded that different species observed in gel electrophoresis are in fact two different gene products rather than post-translationally modified isoforms of the same protein, further support for the presence of phosphorylation comes from additional functional assessments. Anx(At)1 over-produced and isolated from in $N$. benthamiana leaves had more peroxidase activity than recombinant protein produced in $E$. coli and the activity was decreased by dephosphorylation [50]. MS-MS analysis shows that recombinant $\mathrm{Anx}(\mathrm{At}) 1$ produced in E. coli cells was phosphorylated, at Ser-9 (unpublished data, DKP). Thus, phosphorylation clearly reduces the peroxidase activity.

Analysis of Arabidopsis annexin amino acid sequence with NetPhos2.0 ( http://www.cbs.dtu.dk/services/NetPhos) reveals several potential phosphorylation sites both within the N-terminal tail and the C-terminal domain (Figure 2). In contrast, the list of experimentally verified phosphorylation sites of plant annexins is rather short (Table 1), and for Arabidopsis annexins the sites do not perfectly overlap with the in silico predictions (Figure 2). In some cases of verified phosphorylation, the specific location has not yet been determined [51]. Known locations of phosphorylation are either on the convex (membrane binding) side or the concave (membrane distal) side, in agreement with the hypothesis that these are the two sides on the annexin molecule where functional (non-annexin) interactions occur.

Interestingly, the phosphorylation site at Thr-81 in $\operatorname{Anx}(\mathrm{At}) 2$ is situated next to the evolutionary conserved tryptophan at the C-terminal end of helix IE (i.e. on the concave side of the molecule). It is tempting to speculate that the presence of phosphate group at the membrane-distal side may regulate binding to other proteins by certain plant annexins in their membrane-bound state. The Brassica napus annexin is phosphorylated at Ser-300 in the IVDE loop [52], in agreement with in silico predictions using NetPhos2.0. Most notably, this site is situated next to the bidentate residue providing canonical calcium binding in repeat IV of plant annexins. Phosphorylation in the IVDE loop may thus impact on calcium binding or calcium-bound functions of these proteins. Furthermore, the amino acid sequence spanning the IVDE loop and helix IVE has high sequence and structural identity with regions in 14-3-3 proteins (Figure 3) that participate in secretion from adrenal medulla chromoaffin cells [53]. This region also shows high structural similarity between 14-3-3s and annexins, as both proteins adopt the fold of helix bundles with an overall molecular shape that has a concave and a convex side. The overall fold and location of Ser-316 in Anx(At)4 and its counterpart in the 14-3-3 proteins is essentially the same, situated on the concave side. The high conservation of the C-terminal sequence both in animal and in plant annexins makes it a likely candidate for involvement in calcium-induced exocytosis. While all verified phosphorylation sites have only been observed with one particular Arabidopsis annexin, it is intriguing that many of the phosphorylated motifs are conserved in other plant annexins (including Arabidposis), and one would thus expect that these may be confirmed in a systematic assessment.

Interaction of annexins with components of signaling pathways 
Putative kinase or phosphatase targets are frequently identified through interaction with the respective enzyme. For example, in order to establish a map of phosphorylation targets in rice, proteins were identified that interact with kinases immobilised on an affinity resin [54]. Such interacting proteins may not in all cases be substrates of phosphatases/kinases, but rather elements of a structural scaffold that constitutes a certain (de-)phosphorylation pathway. In an effort to screen the rice proteome for phosphatase/kinase substrates, rice annexin Os05g31750, has been found to interact with any of the 23 tested kinases, namely: receptor like kinase (RLK) Os01g02580, Sterile 20 (Ste20)-like kinase Os10g37480, SPK-3 kinase Os01g64970 and casein kinase Os01g28950 [54]. Notably, Os05g31750 was the only rice annexin identified as a substrate for these (de-)phosphorylating enzymes.

Rice annexin Os05g31750 is a homolog of Arabidopsis Anx(At)4, and possesses a very short Nterminal domain (Figure 4). However, several potential phosphorylation sites are located in the Nterminal domain, which is engaged in protein-protein interactions. Its interaction with calcium/calmodulin depedent SPK3 (Os01g64970) and casein kinase Os01g38950 can suggest that annexin is involved in calcium-dependent and independent signaling cascades. The association of rice annexin with Ste20-like kinase (SLK) agrees with the putative involvement in plant stress responses as well as apolar growth. The Ste20 in yeast has been implicated in environmental stress control of cell polarity at various stages of cell cycle possibly due to interaction with cytoskeleton and apoptosis [55]. Ste20 was originally identified in budding yeast as a protein kinase that transmits the pheromone signal from the $\beta / \gamma$ subunit of a G-protein to downstream components of the signaling pathway [56]; subsequently its homologues SLKs were also found in animal and in plant genomes (28 and 11 genes, respectively) [57, 58]. Since SLKs and annexins each interact with the cytoskeleton, it is likely that a complex comprising both proteins is involved in cytoskeleton rearrangement upon stimulation.

\section{Differential/polar growth}

Early work on animal annexins focused on their calcium-dependent membrane interactions, especially membrane aggregation and membrane fusion activities that suggested a role for annexins in mediating secretion. Indeed, annexin A7, one of the first annexins characterized, has an established role in secretion in various cell types, which has been linked to GTP- and calciummediated membrane fusion and channel activities [59-61]. There are now numerous examples of other individual animal annexins that function in localized secretion to an apical domain. For example, annexin A2 and A13b associate with lipid microdomains and are required for secretion to an apical domain in various cell types [62-65].

Plant cell growth requires the delivery of secretory vesicles to expanding membranes and secreted polysaccharides to expanding walls. Regulated secretion does indeed exist in addition to constitutive secretion in plant cells [66, 67]. In maize coleoptiles, it appears to involve calciumdependent steps as well as steps controlled by GTP [68]. In regulating secretion, GTP may target a number of proteins including small $G$ proteins such as ROP-GTPase, and possibly also certain annexins that bind GTP [69-71].

\section{Annexin involvement in secretion in plant cells}

Clearly, plant annexins have many of the protein activities that are likely to be important for regulating and directing secretion in plant cells, such as F-actin binding, GTP-binding, calcium and plasma membrane binding. The first experimental evidence that annexins could participate in Golgi-mediated secretion came from early studies indicating that high levels of plant annexins are localized in a variety of secretory cell types [72, 73] and that maize annexins can aggregate liposomes in a calcium-dependent manner [74]. For example, pea annexins occur in root cap cells, epidermal cells, and developing vascular cells and are associated with Golgi and plasma membranes 
[73]. Arabidopsis annexins Anx(At)1 and Anx(At)2 are strongly localized in epidermal cells of roots and hypocotyls, root hairs, and in peripheral root cap cells at the same time as these cells are actively secreting as judged by the co-localization of labeled polysaccharides [75, 76]. Along these lines, the strongest evidence for plant annexin involvement in regulated secretion is the in vitro demonstration of annexin, calcium and GTP control of fucose secretion in maize root cap cells [77].

\section{Annexins as mediators of directed secretion}

Distinct secretory pathways deliver polysaccharides and non-polysaccharide components to the extracellular matrix (ECM) [78]. Thus, in addition to mediating the secretion of newly synthesized wall materials and plasma membrane, another potential secretory role for plant annexins is the delivery of a wide range of signaling molecules, such as wall-modifying enzymes such as expansins and extensins, arabinogalactan proteins to the ECM, and receptors and transporters to the plasma membrane. Annexins are important regulators of endocytosis in animal cells [79]. They may have a similar role in plants, maintaining polarity in receptors and auxin transporters. In conclusion, there is substantial correlative evidence suggesting a role for annexin in directed secretion in addition to the in vitro evidence for direct annexin mediation of regulated secretion in root cap cells. However, there is still a significant lack of genetic evidence for a specific plant annexin requirement in these processes. There is a need for data from T-DNA or RNAi mutants showing that a lack of a particular annexin results in defects in the secretory process to establish an in vivo role for a specific annexin(s) in exocytosis.

\section{Annexins are localized at the tips of growing cells}

Not only are plant annexins expressed in cells that are highly secretory, but their localization corresponds with the directionality of that secretion; e.g., they are concentrated at the extreme tips of polarly growing cells. Annexin has been localized in the expanding tip region in pollen tubes, root hairs and fern rhizoids, all of which require calcium for the tip-focused delivery of secretory vesicles [72, 76, 80]. To the extent that annexins mediate secretion, their asymmetric distribution in vivo would predict the directionality of the secretion process in cells. Polarized or asymmetric protein localization of both animal and plant annexins has often been demonstrated [73, 80-82].

\section{Annexins as F-actin binding proteins}

Another property of certain plant annexins that could be important when considering a role for annexins in secretion is their ability to bind F-actin. In plants, many studies point to the maintenance of calcium and $\mathrm{pH}$ gradients for establishment of polarity and directing localized secretion and it is also clear that the cytoskeleton via rearrangements and secretory vesicle delivery is important for polarity establishment and directed secretion and growth in plant cells [83]. Actin binding is a well established biochemical property for certain animal annexins (reviewed by [84]) and this property has also been documented for a number of plant annexins (recently reviewed in [85]). Thus far, annexins from tomato, zucchini and Mimosa have all been shown to bind F-actin in vitro. Notably, zuchinni annexins were the first plant annexins shown to bind plant F-actin, and this binding was released by high salt conditions [86]. The other F-actin binding protein in this study was an N-1-Naphthylphthalamic acid (NPA)-binding protein, which was also eluted from an F-actin affinity column by high salt treatment. Calcium-dependency of F-actin binding was first demonstrated for tomato annexins [69]. A Mimosa annexin was also shown to bind F-actin in a $\mathrm{Ca}^{2+}$-dependent manner [48]. This study on Mimosa annexin provided the first evidence that plant annexins can mediate calcium-induced actin bundling in vitro. In maize coleoptiles, actin bundling is induced in epidermal cells during growth inhibition [87] thus certain plant annexins could inhibit cell elongation via affecting actin bundling properties. In animal cells, an exciting recent report indicates that annexin A1 is able to inhibit secretion of the hormone, adrenocorticotrophin, via phosphorylation-dependent translocation of this annexin to the membrane where it increases the 
level of actin polymerization causing inhibition of exocytotic release of the hormone [88]. This finding may have far-reaching consequences for the role that plant annexins might play in regulated exocytosis. Since there are many other functions for actin in plant growth and development, it will be important to determine which, if any, plant annexins indeed interact with the actin cytoskeleton in vivo and what the consequences of this interaction are in regulating cytoskeletal rearrangement, vesicle trafficking and membrane architecture.

\section{Lipid microdomains as places of initiation of polar growth and damage}

Association with lipid microdomains called detergent-resistant membranes or lipid rafts appears to be important for distributing some animal annexins asymmetrically within cellular membranes. This allows them to function in localized secretion and coordinated signaling. Lipid rafts are biochemically defined as a membrane fraction that is insoluble in non-ionic detergent. This fraction is typically enriched in cholesterol, saturated phospholipids, sphingolipids, and glycolipids as well as in glycophosphatidylinositol (GPI) -anchored proteins and other specific membrane proteins. The existence of lipid rafts in animal cells was originally a controversial idea. There is now increasing evidence supporting an in vivo role for these rafts as sites for signaling, exocytosis, endocytosis, and pathogen entry. Animal proteins associated with these specialized membrane domains appear to facilitate polarity and direct apical vesicular transport. Certain animal annexins associate with lipid rafts in different cell types in a functionally important manner. For example, annexin A2 is required for apical transport of raft-associated sucrase-isomaltase-carrying vesicles in polarized epithelial cells [65]. Lipid rafts are also believed to provide distinct domains of the plasma membrane spatially segregating signaling events. Thus, another important functional role for annexins may be their reversible association and stabilization of lipid rafts where they could sequester and/or compartment signaling components [89, 90].

Do plant cells have such rafts in their plasma membranes? The answer to this question appears to be affirmative. Specifically, plant cells have sterol-enriched membrane microdomains [91] that appear to be important in protein sorting to the plant plasma membrane [92, 93]. Specialized membrane domains play a role in polar secretion and growth in pollen tubes [94] and based on observations of mutants in sterol biosynthesis. Sterol-enriched lipid domains are critical for the polar transport of key signaling molecules [95, 96]. In addition, SNAREs (soluble $N$-ethylmaleimide-sensitive factor attachment protein receptors) are a family of proteins involved in membrane trafficking and appear to function in exocytosis via lipid rafts [97]. In plant cells, they are associated with lipid rafts [98]. Formation of lipid microdomains has also been suggested to be a required step in biotic infection of plant cells [99] which is interesting considering the speculation that certain plant annexins might function via lipid microdomains. Thus far, only a few studies of plant lipid rafts have identified an annexin protein associated with a lipid raft membrane preparation [100, 101].

\section{Membrane-associated functions RedOx processes at the plasma membrane}

An annexin protein associated with a lipid raft membrane preparation in Medicago [100]. A complete plasma membrane redox system occurs within lipid rafts, and certain plant annexins function in reactive oxygen species (ROS) signaling pathways by reducing the levels of $\mathrm{H}_{2} \mathrm{O}_{2}$ [102-104]. They may do so via association with raft localized membrane redox systems. Lipid raft polarization of ROS signaling system is required for pollen tube tip growth [105].

The finding is an interesting overlap with glycosyltransferases in plasma membranes of plants that catalyse the synthesis of cell wall sugars such as cellulose and callose. A redox-dependent model of cellulose synthase activation had been proposed [106, 107], and the co-localisation of cotton annexins with callose synthase [47, 71, 108, 109] has implicated annexin involvement in the regulation of glucan synthesis in wound healing and stress situations. 
How plant annexins may regulate redox chemistry at the atomic level remains an open question. Based on the information from three-dimensional crystal structures, a putative redox-active cluster is a conserved feature in many (but not all) plant annexins. The cluster is formed by two adjacent cysteine residues and the sulphur of a nearby methionine residue, located in helices IIB and IIIE [9]. The existence of an electron transfer pathway to/from this $\mathrm{S}_{3}$ cluster remains to be experimentally validated. Intriguingly, these cysteine residues in $\mathrm{Anx}(\mathrm{At}) 1$ can be glutathionylated in vivo upon abscisic acid stimulation. Cysteine residues may play a pivotal role in the regulation of biological activities of different proteins. S-glutathionylation of recombinant $\operatorname{Anx}(\mathrm{At}) 1$ results in a decrease of the calcium affinity and thus influence its canonical functions [17].

In a more direct way, plant annexins could respond to oxidative stress at the membrane. Oxidative stress in the form of ROS affects the structural integrity of phospholipid membranes through lowering the lipid packing order inside the membrane and induction of phase separation $[110,111]$. It is an intriguing thought that the peroxidase activity of annexins may recognise or rescue peroxidated lipids in a membrane-bound state and thus contribute to membrane stability. Alternatively, a protective process by formation of $2 \mathrm{~d}$-crystalline patches on peroxidated membranes or a resealing mechanism (see below) could be envisioned where some sort of recognition of peroxidated lipids is involved.

\section{Annexins in membrane destabilisation}

The ability of annexins to permeabilise membranes was discovered more than 20 years ago [112], and has recently been brought back into attention in the area of plant annexins [16]. Electrophysiology, mainly patch clamp (lipid seal on the tip of glass capillaries) and planar lipid bilayers have been used to probe this activity. These were single channel conductivities of ca 30 piko-Siemens (pS), as well as selectivity for calcium [113-115], leading to the assignment of a "calcium-selective ion channel” role for annexins.

However, conclusions in those studies (and subsequent papers and reviews referring to those results) have exclusively focused on isolated current recordings where channel opening and closing features have been observed. The many membrane preparations where no permeabilisation or burstlike activities are observed have not been taken into account. Clearly, this ignores a large proportion of observations that are not in agreement with the definition of an ion channel. In our opinion, the term ion channel is not appropriate for annexins.

For example, comparing the ion selectivities between annexins and conventional ion channels, there are differences at the order of magnitudes, thus dwarfing the ion selectivity of annexin "channels" (see Table 2). In our own patch clamp experiments with mammalian annexins, small channel events with 2-3 pS openings and closings have frequently occurred, and many preparations have no channel activities at all [116].

In the absence of a useful model of putative annexin channels, it is difficult to estimate what the expected conductance of an annexin single channel should be. One hypothesis, which was subject to a controversial debate about 15 years ago, suggested the hydrophilic pore of annexins as the ion pathway within the permeabilising species [117]. Theoretical estimations based on crystal structures of annexins allow the assumption of a pore radius of $1 \AA$ and a length of $80 \AA$ (annexin height plus membrane thickness). These dimensions yield a maximum conductivity of $\sim 4 \mathrm{pS}$. It would thus require a much wider pore and/or shorter pore to achieve conductivities at the order of $30 \mathrm{pS}$.

Electrophysiology studies with annexins further seem to be in agreement about symmetrical I-Vrecordings with respect to the holding potential applied. Since the protein is being applied only to one bath solution it would constitute an asymmetric channel with respect to the membrane. Therefore, one would expect asymmetric I-V-relations, unless the protein either inserts symmetrically into the bilayer (one molecule on the cis and one on the trans side, head-to-head or tail-to-tail), or complete unfolds into a symmetrically membrane-inserted structure. There is no clear evidence for either. A third option in this context would be a local membrane disruption that is caused and/or stabilised by peripherally bound annexin molecules. Earlier studies have promoted 
the idea of local electroporation of the membrane caused by the electrostatic potential of the protein $[118,119]$. A similar situation may be achieved by a spontaneous rupture of the membrane which is transiently stabilised by annexin molecules.

Lastly, since the detailed molecular events surrounding annexin electrophysiology preparations are still not clear, there is further need for caution to avoid confusion with artificial channels. Ionic selectivity of patch clamp preparations with similar characteristics to those of nicotinic acetylcholine channels have been observed in a patch clamp method that provides Giga-Ohm seals [120]. This study provides evidence that there is a current flow between the membrane layer and the frame (e.g. glass pipette) in these electrophysiological recordings. We have therefore suggested that annexins (as bulk matter) may modulate membrane resistance through increasing the pressure of the seal against the surrounding frame [116]. At the same time, the interface between the frame and the membrane in these seals represents a local membrane rupture and annexins may also act in their role as stabilisers in these areas, and locally stabilise an ion permeable pore. Since all annexin electrophysiology studies agree on a clear preference of cation over anion flow through the membrane. It is an intriguing thought to hold the negatively charged phospholipid head groups for this selection effect responsible.

\section{Annexins in membrane stabilisation}

A rather common phenomenon has been observed in the preparation of patch clamp seals when probing annexin membrane interactions electrophysiologically, but ignored when analysing the annexin-mediated permeabilisation of membranes. Depending on the $\mathrm{pI}$ of a protein and the $\mathrm{pH}$ of the system, the protein possesses an overall charge and as such will follow the electric potential. The annexins are typically added to one side of a two compartment system separated by a membrane preparation. The protein molecules will be collectively driven to the membrane surface at a certain transmembrane potential, and forced away from the surface at potentials with the opposite sign. The voltage-dependent binding effect of vertebrate annexins leads to a significant increase in the resistance of the membrane preparation, indicative of a protein layer sealing one side of the membrane bilayer [121]. Under in vivo conditions with apoptotic cells, the variation of the transmembrane potential indeed affects the membrane binding of annexin A5, but also that of structurally unrelated proteins that employ a similar phosphatidylserine-dependent membrane binding mechanism [122].

Future electrophysiological experiments with plant annexins should follow up this rather neglected interlink between annexins and transmembrane potential. Oxidative stress and lipid peroxidation are likely to alter the surface charge density of membranes either directly by generation of charged groups on the phospholipid molecules, or indirectly by modification of transmembrane ion channels [123]. This may open a further avenue of activity for plant annexins in oxidative stress.

\section{A role for plant annexins in membrane resealing}

Another membrane associated function demonstrated for animal annexins is participation in membrane repair together with synaptotagmins [124-126]. Synaptotagmins are a family of calcium- and phospholipid binding proteins involved in membrane-trafficking. They consist of an N-terminal transmembrane domain and two tandem cytoplasmic $\mathrm{C} 2$ domains known to mediate calcium-dependent binding to negatively charged phospholipids. They were proposed to function as calcium sensor during vesicle exo- and endocytosis. In contrast to mammals, plant synaptotagmins constitute a less divergent family with four and eight members in Arabidopsis and rice, respectively [127]. Based on extensive structural similarities between animal and plant synaptotagmins, the latter are likely to possess similar roles, suggesting conservation of membrane repair mechanisms between animal and plant cells [128]. It has been proposed that plant annexins may function in this process of membrane resealing as well [129, 130]. Synaptotagmin also plays a role in membrane resealing in response to cold treatment [131] where it is associated with lipid rafts in plants cells. Cold treatment induces an increase in their 
association with these rafts [132]. Interestingly, annexins associate with wheat membranes as intrinsic proteins after cold treatment [133] and have been proposed to function in response of wheat plants to cold [134], albeit other stimuli have also been reported to up-regulate plant annexin expression in Mimosa [48]. Thus another potential function for certain plant annexins in association with lipid rafts might be a role in membrane repair, which needs to be further investigated. The extent to which plant annexins function via lipid rafts is an open question, and one complication in determining the importance of the connection between lipid rafts and annexin function is that plant annexins might associate with these rafts in a signal-dependent fashion. Thus, it will be important to determine on an individual basis which of the plant annexins associate with lipid rafts to evaluate whether they mediate directed secretion via a similar mechanism as proposed for the animal annexin A2 and annexin A13b, or regulated signaling as proposed for annexin A2 [125].

\section{Conclusions and Outlook}

The available data on plant annexin phosphorylation indicates modification of either the convex or the concave side of the molecule. Therefore, consequences for membrane and calcium binding can be expected, thus resulting in altered translocation. The concave side of the plant annexin molecule may also be a prime site of interaction with other proteins, subject to phosphorylation-dependent regulation.

The structural similarity of the C-terminal helix IVD with a region in 14-3-3 proteins provides a new link to the involvement in signaling pathways. 14-3-3 proteins have the ability to bind a multitude of functionally diverse phosphorylated signaling proteins. However, they can themselves be phosphorylated and thus be recognised by their own phosphate recognition motifs. It is an intriguing hypothetical thought that plant annexins such as Anx(At)4 may act as a surrogate for the homo-recognition of $14-3-3$ s and thus participate in particular signaling pathways, similar to other binding partners of 14-3-3s, such as histone deacetylase [135, 136], telomerase [137] and others [138-140].

The expected fine-tuning of annexin translocation and protein-protein or protein-ligand interactions through phosphorylation may help to establish the required infrastructure for processes in polar growth of plant cells. Other factors that may help to recruit plant annexins to sites of increased growth may be coming from the recognition of lipid microdomains, perhaps through the recognition of glucosyl groups of glycolipids. Vertebrate [141] and parasite annexins [142] recognise oligosaccharides, and preliminary data indicate that this is also true for bell pepper and cotton annexins (Hofmann, unpublished).

Apart from taking part in signaling pathways that control the sites of growth of the cell wall, plant annexins are also likely to contribute scaffold functionality at those sites where the plasma membrane is in a transformative stage. As such there may be little difference at the level of molecular events between an expanding plant cell wall and a site of spontaneous membrane rupture where annexins contribute to resealing. This argument would be taken to its extreme by the suggestion that these are in principle the same actions performed by annexins in electrophysiological preparations with artificial membranes where small ruptures may be stabilised by annexins to a certain extent thereby transiently allowing ion flow. Future experiments to elucidate the role of plant annexins by electrophysiology should definitely address in vivo membranes. For example in a whole cell patch clamp arrangement with and without constitutively expressed annexins.

Lastly, there is general agreement about the protective involvement of plant annexins in oxidative stress response, and post-translational modification of the cysteine residues in the $\mathrm{S}_{3}$ cluster by glutathionylation may offer a generic mechanism of eliciting a stress-related response by plant annexins. Future research should investigate which annexin activities are modified upon glutathionylation. Another interesting mechanism may come about if plant annexins are able to 
recognise or rescue peroxidated phospholipids in their capacity as peroxidases.

In our opinion, further investigation of this protein family in plants will be a rewarding endeavour and provide exciting insights that may even cross-fertilise thoughts in the area of their vertebrate relatives.

\section{Acknowledgements}

The work was partially supported by Grants: N N301 567540 to DKP from the Polish Ministry of Education and Science.

\section{References}

[1] A. Cantero, S. Barthakur, T.J. Bushart, S. Chou, R.O. Morgan, M.P. Fernandez, G.B. Clark, S.J. Roux, Expression profiling of the Arabidopsis annexin gene family during germination, deetiolation and abiotic stress, Plant Physiol Biochem 44 (2006), 13-24.

[2] S.E. Moss, R.O. Morgan, The annexins, Genome Biol 5 (2004), 219.

3. Hofmann A, Huber R (2003) Structural conservation and functional versatility: allostery as a common annexin feature. In: Bandorowicz-Pikula J, editor. Annexins: biological importance and annexin-related pathologies. Landes Bioscience, Georgetown, TX. pp. 38-60.

[4] A. Hofmann, Annexins in the plant kingdom - perspectives and potentials, Annexins 1 (2004), 51-61.

[5] J.C. Mortimer, A. Laohavisit, N. Macpherson, A. Webb, C. Brownlee, N.H. Battey, J.M. Davies, Annexins: multifunctional components of growth and adaptation, J Exp Bot 59 (2008), 533-544.

[6] A. Laohavisit, J. Davies, Multifunctional annexins, Plant Sci. 177 (2009), 532-539.

[7] A. Laohavisit, J.M. Davies, Annexins, New Phytol 189 (2011), 40-53.

[8] A. Hofmann, J. Proust, A. Dorowski, R. Schantz, R. Huber, Annexin 24 from Capsicum annuum. X-ray structure and biochemical characterization, J. Biol. Chem. 275 (2000), 8072-8082. [9] A. Hofmann, D.P. Delmer, A. Wlodawer, The crystal structure of annexin Gh1 from Gossypium hirsutum reveals an unusual S3 cluster, Eur. J. Biochem. 270 (2003), 2557-2564.

[10] N. Hu, A. Yusof, A. Winter, A. Osman, A. Reeve, A. Hofmann, The crystal structure of calcium-bound annexin Gh1 from Gossypium hirsutum indicates different mechanisms of membrane binding in plant and animal annexins, J. Biol. Chem. 283 (2008), 18314-18322.

[11] E.J. Levin, D.A. Kondrashov, G.E. Wesenberg, G.N.J. Phillips, Ensemble refinement of protein crystal structures: validation and application, Structure 15 (2007), 1040-1052.

[12] D.P. Delmer, T.S. Potikha, Structures and functions of annexins in plants, Cell. Mol. Life Sci. 53 (1997), 546-553.

[13] N. Dabitz, N.J. Hu, A.M. Yusof, N. Tranter, A. Winter, M. Daley, O. Zschörnig, A. Brisson, A. Hofmann, Structural determinants for plant annexin-membrane interactions, Biochemistry 44 (2005), 16292-16300.

[14] A. Hofmann, S. Ruvinov, S. Hess, R. Schantz, D.P. Delmer, A. Wlodawer, Plant annexins form calcium-independent oligomers in solution, Protein Sci. 11 (2002), 2033-2040.

[15] X. Gidrol, P. Sabelli, Y. Fern, A. Kush, Annexin-like protein from Arabidopsis thaliana rescues delta oxyR mutant of Escherichia coli from H2O2 stress, Proc. Natl. Acad. Sci. 93 (1996),

11268-11273.

[16] A. Laohavisit, J.C. Mortimer, V. Demidchik, K.M. Coxon, M.A. Stancombe, N. Macpherson, C. Brownlee, A. Hofmann, A.A.R. Webb, H. Miedema et al., Zea mays annexins modulate cytosolic free Ca2+ and generate a Ca2+-permeable conductance, Plant Cell 21 (2009), 479-493.

[17] D. Konopka-Postupolska, G. Clark, G. Goch, J. Debski, K. Floras, A. Cantero, B. Fijolek, S. Roux, J. Hennig, The role of annexin 1 in drought stress in Arabidopsis, Plant Physiol 150 (2009), 1394-1410. 
[18] B. Rothhut, Participation of annexins in protein phosphorylation, Cell Mol Life Sci 53 (1997), 522-526.

[19] Y. Ando, S. Imamura, M. Owada, R. Kannagi, Ca2+-induced intracellular crosslinking of lipocortin I by tissue transglutaminase in A431 cells, J. Biol. Chem 266 (1991), 1101-1108.

[20] B.M. Wice, J.I. Gordon, A strategy for isolation of cDNAs encoding proteins affecting human intestinal epithelial cell growth and differentiation: characterization of a novel gut-specific Nmyristoylated annexin, J Cell Biol 116 (1992), 405-422.

[21] K. Fiedler, F. Lafont, R. Parton, K. Simons, Annexin XIIIb: a novel epithelial specific annexin is implicated in vesicular traffic to the apical plasma membrane, J. Cell Biol 128 (1995), 1043-1053.

[22] D.M. Sullivan, N.B. Wehr, M.M. Fergusson, R.L. Levine, T. Finkel, Identification of oxidantsensitive proteins: TNF-alpha induces protein glutathiolation, Biochemistry 39 (2000),

11121-11128.

[23] S.Y. Chuah, C.J. Pallen, Calcium-dependent and phosphorylation-stimulated proteolysis of lipocortin I by an endogenous A431 cell membrane protease, J Biol Chem 264 (1989), 21160-21166.

[24] L. Liu, A.B. Fisher, U.J. Zimmerman, Regulation of annexin I by proteolysis in rat alveolar epithelial type II cells, Biochem Mol Biol Int 36 (1995), 373-381.

[25] D. Schlaepfer, H. Haigler, Characterisation of Ca2+ -dependent phospholipid binding and phosphorylation of lipocortin I, J. Biol. Chem 262 (1987), 6931-6937.

[26] Y. Ando, S. Imamura, Y. Hong, M. Owada, T. Kakunaga, R. Kannagi, Enhancement of calcium sensitivity of lipocortin I in phospholipid binding induced by limited proteolysis and phosphorylation at the amino terminus as analyzed by phospholipid affinity column chromatography., J. Biol. Chem. 264 (1989), 6948-6955.

[27] J. Barnes, Gomes A.V., Proteolytic signals in the primary structure of annexins, Mol. Cell. Bioch. 231 (2002), 1-7.

[28] M. Kaetzel, Y. Mo, T. Mealy, B. Campos, W. Bergsma-Schutter, A. Brisson, J. Dedman, B. Seaton, Phosphorylation mutants elucidate the mechanism of annexin IV-mediated membrane aggregation, Biochemistry 40 (2001), 41925-44199.

[29] V. Gerke, S.E. Moss, Annexins: from structure to function, Physiol. Rev. 82 (2002), 331-371.

[30] S.A. Johnstone, I. Hubaishy, D.M. Waisman, Phosphorylation of annexin II tetramer by protein kinase C inhibits aggregation of lipid vesicles by the protein, J Biol Chem 267 (1992), 25976-25981.

[31] W. Wang, C. Creutz, Regulation of the chromaffin granule aggregating activity of annexin A1 by phosphorylation, Biochemistry 31 (1992), 9934-9939.

[32] H. Caohuy, H.B. Pollard, Activation of annexin 7 by protein kinase c in vitro and in vivo, J. Biol. Chem. 276 (2001), 12813-12821.

[33] A.B. Deora, G. Kreitzer, A.T. Jacovina, K.A. Hajjar, An annexin 2 phosphorylation switch mediates its p11-dependent translocation to the cell surface, J. Biol. Chem. (2004), .

[34] I. Hubaishy, P. Jones, J. Bjorge, C. Bellagamba, S. Fitzpatrick, D. Fujita, D. Waisman, Modulation of annexin II tetramer by tyrosine phosphorylation, Biochemistry 34 (1995), 14527-14534.

[35] M. Graauw, I. Tijdens, M. Smeets, P. Hensbergen, A. Deelder, B. van de Water, Annexin A2 phosphorylation mediates cell scattering and branching morphogenesis via cofilin activation, Mol. Cell. Biol. 28 (2008), 1029-1040.

[36] U. Rescher, C. Ludwig, V. Konietzko, A. Kharitonenkov, V. Gerke, Tyrosine phosphorylation of annexin A2 regulates Rho-mediated actin rearrangement and cell adhesion, J Cell Sci 121 (2008), 2177-2185.

[37] G.R. Yan, W. Luo, X.J. Luo, Y. Cao, [Epstein-Barr Virus-encoded Latent Membrane Protein 1 Mediates Serine-Phosphorylation of Annexin I by Activating Protein Kinase C.], Ai Zheng 26 
(2007), 679-682.

[38] W. Luo, G. Yan, L. Li, Z. Wang, H. Liu, S. Zhou, S. Liu, M. Tang, W. Yi, Z. Dong et al., Epstein-Barr virus latent membrane protein 1 mediates serine 25 phosphorylation and nuclear entry of annexin A2 via PI-PLC-PKCalpha/PKCbeta pathway, Mol Carcinog 47 (2008), 934-946. [39] L.C. Alldridge, H.J. Harris, R. Plevin, R. Hannon, C.E. Bryant, The Annexin Protein Lipocortin 1 Regulates the MAPK/ERK Pathway, J. Biol. Chem. 274 (1999), 37620-37628. [40] E. Solito, H.C. Christian, M. Festa, A. Mulla, T. Tierney, R.J. Flower, J.C. Buckingham, Posttranslational modification plays an essential role in the translocation of annexin A1 from the cytoplasm to the cell surface, FASEB J 20 (2006), 1498-1500.

[41] L. Szilak, J. Moitra, D. Krylov, C. Vinson, Phosphorylation destabilizes a-helices, Nature Struct. Biol. 4 (1997), 112-114.

[42] C. Andrew, J. Warwicker, G. Jones, A. Doig, Effect of phosphorylation on alpha-helix stability as a function of position, Biochemistry 41 (2002), 1897-1905.

[43] M. Dorovkov, A. Ryazanov, Phosphorylation of annexin I by TRPM7 channel-kinase, J. Biol. Chem. 279 (2004), 50643-50646.

[44] M. Dorovkov, A. Kostyukova, A. Ryazanov, Phosphorylation of annexin A1 by TRPM7 kinase: A switch regulating the induction of an alpha-helix, Biochemistry 50 (2011), 2187-2193.

[45] R. Muimo, Z. Hornickova, C.E. Riemen, V. Gerke, H. Matthews, A. Mehta, Histidine Phosphorylation of Annexin I in Airway Epithelia, J. Biol. Chem. 275 (2000), 36632-36636.

[46] L. Varticovsky, S. Chahwala, M. Whitman, L. Cantley, D. Shinder, E. Chow, L. Sinclair, R. Pepinsky, Localisation of sites in human lipocortin I that are phosphorylated by protein tyrosine kinases and protein kinase A and C, Biochemistry 27 (1988), 3682-3690.

[47] A. Andrawis, M. Solomon, D. Delmer, Cotton fibre annexins: a potential role in the regulation of callose synthase, Plant J. 3 (1993), 763-772.

[48] D. Hoshino, A. Hayashi, Y. Temmei, N. Kanzawa, T. Tsuchiya, Biochemical and immunohistochemical characterization of Mimosa annexin, Planta 219 (2004), 867-875.

[49] S. Lee, E.J. Lee, E.J. Yang, J.E. Lee, A.R. Park, W.H. Song, O.K. Park, Proteomic identification of annexins, calcium-dependent membrane binding proteins that mediate osmotic stress and abscisic acid signal transduction in Arabidopsis, Plant Cell 16 (2004), 1378-1391. [50] K.M. Gorecka, D. Konopka-Postupolska, J. Hennig, R. Buchet, S. Pikula, Peroxidase activity of annexin 1 from Arabidopsis thaliana, Biochem Biophys Res Commun 336 (2005), 868-875.

[51] S. Irar, E. Oliveira, M. Pagès, A. Goday, Towards the identification of late-embryogenicabundant phosphoproteome in Arabidopsis by 2-DE and MS, Proteomics 6 Suppl 1 (2006), S175-85.

[52] G.K. Agrawal, J.J. Thelen, Large scale identification and quantitative profiling of phosphoproteins expressed during seed filling in oilseed rape, Mol Cell Proteomics 5 (2006), 2044-2059.

[53] D. Roth, A. Morgan, R. Burgoyne, Identification of a key domain in annexin and 14-3-3 proteins that stimulate calcium-dependent exocytosis in permeabilized adrenal chromaffin cells, FEBS Lett. 320 (1993), 207-210.

[54] J.S. Rohila, M. Chen, S. Chen, J. Chen, R. Cerny, C. Dardick, P. Canlas, X. Xu, M. Gribskov, S. Kanrar et al., Protein-protein interactions of tandem affinity purification-tagged protein kinases in rice, Plant J 46 (2006), 1-13.

[55] S. Ahn, W.L. Cheung, J. Hsu, R.L. Diaz, M.M. Smith, C.D. Allis, Sterile 20 kinase phosphorylates histone $\mathrm{H} 2 \mathrm{~B}$ at serine 10 during hydrogen peroxide-induced apoptosis in $S$. cerevisiae, Cell 120 (2005), 25-36.

[56] E. Leberer, D. Dignard, D. Harcus, D.Y. Thomas, M. Whiteway, The protein kinase homologue Ste20p is required to link the yeast pheromone response G-protein beta gamma subunits to downstream signalling components, EMBO J 11 (1992), 4815-4824.

[57] E. Delpire, The mammalian family of sterile 20p-like protein kinases, Pflügers Archiv Europ. 
Jour. Physiol. 458 (2009), 953-967.

[58] P. Karpov, A. Emets, V. Matusov, A. Yu Nyporko, E. Nadezhdina, Y. Blume, Bioinformatics search for plant homologues of Ste20-like serine/threonine protein kinases, Cytol. Genet. 43 (2009), 419-428.

[59] H. Caohuy, M. Srivastava, H.B. Pollard, Membrane fusion protein synexin (annexin VII) as a Ca2+/GTP sensor in exocytotic secretion, Proc Natl Acad Sci U S A 93 (1996), 10797-10802.

[60] M. Srivastava, M. Cartas, T.A. Rizvi, S.P. Singh, D. Serio, V.S. Kalyanaraman, H.B. Pollard, A. Srinivasan, HIV-1 Gag shares a signature motif with annexin (Anx7), which is required for virus replication, Proceedings of the National Academy of Sciences of the United States of America 96 (1999), 2704-2709.

[61] A. Chander, N. Sen, A.R. Spitzer, Synexin and GTP increase surfactant secretion in permeabilized alveolar type II cells, Am J Physiol Lung Cell Mol Physiol 280 (2001), L991-8. [62] F. Lafont, S. Lecat, P. Verkade, K. Simons, Annexin XIIIb associates with lipid microdomains to function in apical delivery, J. Cell Biol 142 (1998), 1413-1427.

[63] P.J. Plant, F. Lafont, S. Lecat, P. Verkade, K. Simons, D. Rotin, Apical Membrane Targeting of Nedd4 Is Mediated by an Association of Its C2 Domain with Annexin XIIIb, J Cell Biol 149 (2000), 1473-1484.

[64] Y. Noda, Y. Okada, N. Saito, M. Setou, Y. Xu, Z. Zhang, N. Hirokawa, KIFC3, a microtubule minus end-directed motor for the apical transport of annexin XIIIb-associated Triton-insoluble membranes, J Cell Biol 155 (2001), 77-88.

[65] R. Jacob, M. Heine, J. Eikemeyer, N. Frerker, K.P. Zimmer, U. Rescher, V. Gerke, H.Y. Naim, Annexin II is required for apical transport in polarized epithelial cells, J. Biol. Chem. 279 (2004), 3680-3684.

[66] M. Steer, The role of calcium in exocytosis and endocytosis in plant cells, Physiologia Plantarum 72 (1988), 213-220.

[67] G. Thiel, N. Battey, Exocytosis in plants, Plant Mol Biol 38 (1998), 111-125.

[68] J. Sutter, U. Homann, G. Thiel, Ca2+-stimulated exocytosis in maize coleoptile cells, Plant Cell 12 (2000), 1127-1136.

[69] C. Calvert, S. Gant, D. Bowles, Tomato annexins p34 and p35 bind to F-actin and display nucleotide phosphodiesterase activity inhibited by phospholipid binding, Plant Cell 8 (1996), 333-342.

[70] E.K. Lim, M.R. Roberts, D.J. Bowles, Biochemical characterization of tomato annexin p35 Independence of calcium binding and phosphatase activities, J. Biol. Chem. 273 (1998), 34920-34925.

[71] H.S. Shin, R.M. Brown, GTPase activity and biochemical characterization of a recombinant cotton fiber annexin, Plant Physiol. 119 (1999), 925-934.

[72] H. Blackbourn, P. Barker, N. Huskisson, N. Battey, Properties and partial protein sequence of plant annexins, Plant Physiol. 99 (1992), 864-871.

[73] G.B. Clark, M. Dauwalder, S.J. Roux, Purification and immunolocalization of an annexin-like protein in pea seedlings, Planta 187 (1992), 1-9.

[74] H. Blackbourn, N. Battey, Annexin-mediated secretory vesicle aggregation in plants, Physiol. Plant 89 (1993), 27-32.

[75] G.B. Clark, A. Sessions, D.J. Eastburn, S.J. Roux, Differential expression of members of the annexin multigene family in Arabidopsis, Plant Physiol. 126 (2001), 1072-1084.

[76] G. Clark, A. Cantero-Garcia, T. Butterfield, M. Dauwalder, S. Roux, Secretion as a key component of gravitropic growth: implications for annexin involvement in differential growth, Grav. Space Biol. 18 (2005), 113-114.

[77] A. Carroll, C. Moyen, P. van Kesteren, F. Tooke, N. Battey, C. Brownlee, Ca2+, annexins, and GTP modulate exocytosis from maize root cap protoplasts, Plant Cell 10 (1998), 1267-1276. [78] M.R. Leucci, G. Di Sansebastiano, M. Gigante, G. Dalessandro, G. Piro, Secretion marker 
proteins and cell-wall polysaccharides move through different secretory pathways, Planta 225 (2007), 1001-1017.

[79] C.E. Futter, I.J. White, Annexins and Endocytosis, Traffic 8 (2007), 951-958.

[80] G.B. Clark, S. Turnwald, U.K. Tirlapur, C.J. Haas, K. von der Mark, S.J. Roux, R. Scheuerlein, Polar distribution of annexin-like proteins during phytochrome-mediated initiation and growth of rhizoids in the ferns Dryopteris and Anemia, Planta 197 (1995), 376-384.

[81] D. Massey-Harroche, N. Mayran, S. Maroux, Polarized localizations of annexins I, II, VI and XIII in epithelial cells of intestinal, hepatic and pancreatic tissues, J. Cell Sci. 111 (1998), 3007-3015.

[82] G.B. Clark, D.S. Rafati, R.J. Bolton, M. Dauwalder, S.J. Roux, Redistribution of annexin in gravistimulated pea plumules, Plant Physiol Biochem 38 (2000), 937-947.

[83] G. Wasteneys, M. Galway, Remodelling the cytoskeleton for growth and form: An overview with some new views, Ann. Rev. Plant Biol. 54 (2003), 691-722.

[84] M.J. Hayes, U. Rescher, V. Gerke, S.E. Moss, Annexin-actin interactions, Traffic 5 (2004), 571-576.

[85] D. Konopka-Postupolska, Annexins: putative linkers in dynamic membrane-cytoskeleton interactions in plant cells, Protoplasma 230 (2007), 203-215.

[86] S. Hu, S. Brady, D. Kovar, C. Staiger, G. Clark, S. Roux, G. Muday, Identification of plant actin-binding proteins by F-actin affinity chromatography, Plant J. 24 (2000), 127-137.

[87] F. Waller, M. Riemann, P. Nick, A role for actin-driven secretion in auxin-induced growth, Protoplasma 219 (2002), 72-81.

[88] S. McArthur, S. Yazid, H. Christian, R. Sirha, R. Flower, J. Buckingham, E. Solito, Annexin A1 regulates hormone exocytosis through a mechanism involving actin reorganization, FASEB J. 23 (2009), 4000-4010.

[89] E. Babiychuk, A. Draeger, Annexins in cell membrane dynamics: Calcium-regulated association of lipid microdomains, J. Cell Biol. 150 (2000), 1113-1123.

[90] A. Draeger, S. Wray, E.B. Babiychuk, Domain architecture of the smooth-muscle plasma membrane: regulation by annexins, Biochem J 387 (2005), 309-314.

[91] T. Peskan, M. Westermann, R. Oelmüller, Identification of low-density Triton X-100-insoluble plasma membrane microdomains in higher plants, Eur J Biochem 267 (2000), 6989-6995.

[92] S. Mongrand, J. Morel, J. Laroche, S. Claverol, J. Carde, M. Hartmann, M. Bonneu, F. SimonPlas, R. Lessire, J. Bessoule, Lipid rafts in higher plant cells: purification and characterization of Triton X-100-insoluble microdomains from tobacco plasma membrane, J Biol Chem 279 (2004), 36277-36286.

[93] S. Mongrand, T. Stanislas, E.M.F. Bayer, J. Lherminier, F. Simon-Plas, Membrane rafts in plant cells, Trends Plant Sci 15 (2010), 656-663.

[94] B. Kost, E. Lemichez, P. Spielhofer, Y. Hong, K. Tolias, C. Carpenter, N.H. Chua, Rac homologues and compartmentalized phosphatidylinositol 4, 5-bisphosphate act in a common pathway to regulate polar pollen tube growth, J Cell Biol 145 (1999), 317-330.

[95] H. Betts, I. Moore, Plant cell polarity: the ins-and-outs of sterol transport, Curr Biol 13 (2003), R781-3.

[96] U. Fischer, S. Men, M. Grebe, Lipid function in plant cell polarity, Curr Opin Plant Biol 7 (2004), 670-676.

[97] C. Salaün, D.J. James, L.H. Chamberlain, Lipid rafts and the regulation of exocytosis, Traffic 5 (2004), 255-264.

[98] J. Morel, S. Claverol, S. Mongrand, F. Furt, J. Fromentin, J. Bessoule, J. Blein, F. Simon-Plas, Proteomics of plant detergent-resistant membranes, Mol. Cell. Proteom. 5 (2006), 1396-1411.

[99] R. Bhat, M. Miklis, E. Schmelzer, P. Schulze-Lefert, R. Panstruga, Recruitment and interaction dynamics of plant penetration resistance components in a plasma membrane microdomain, Proc. Natl. Acad. Sci. 102 (2005), 3135-3140. 
[100] B. Lefebvre, F. Furt, M. Hartmann, Michaelson, L,V., J. Carde, F. Sargueil-Boiron, M. Rossignol, J. Napier, J. Cullimore, J. Bessoule et al., Characterization of lipid rafts from Medicago truncatula root plasma membranes: A proteomic study reveals the presence of a raft-associated redox system, Plant Physiol. 144 (2007), 402-418.

[101] F. Demir, Lipid rafts in Arabidopsis thaliana leaves, PhD Thesis (2010).

[102] S.K. Jami, G.B. Clark, S.A. Turlapati, C. Handley, S.J. Roux, P.B. Kirti, Ectopic expression of an annexin from Brassica juncea confers tolerance to abiotic and biotic stress treatments in transgenic tobacco, Plant Physiol Biochem 46 (2008), 1019-1030.

[103] K. Divya, S.K. Jami, P.B. Kirti, Constitutive expression of mustard annexin, AnnBj1 enhances abiotic stress tolerance and fiber quality in cotton under stress, Plant Mol Biol 73 (2010), 293-308.

[104] S.K. Jami, R.D. Hill, P.B. Kirti, Transcriptional regulation of annexins in indian mustard, Brassica juncea and detoxification of ROS in transgenic tobacco plants constitutively expressing AnnBj1, Plant Signal Behav 5 (2010), .

[105] P. Liu, R. Li, L. Zhang, Q. Wang, K. Niehaus, F. Baluska, J. Samaj, J. Lin, Lipid microdomain polarization is required for NADPH oxidase-dependent ROS signaling in Picea meyeri pollen tube tip growth, Plant J. 60 (2009), 303-313.

[106] I. Kurek, Y. Kawagoe, D. Jacob-Wilk, M. Doblin, D. Delmer, Dimerisation of cotton fibre cellulose synthase catalytic subunits via oxidation of the zinc-binding domains, Proc. Natl. Acad. Sci. 99 (2002), 11109-11114.

[107] D. Jacob-Wilk, I. Kurek, P. Hogan, D.P. Delmer, The cotton fiber zinc-binding domain of cellulose synthase A1 from Gossypium hirsutum displays rapid turnover in vitro and in vivo, Proc. Natl. Acad. Sci. 103 (2006), 12191-12196.

[108] H. Shin, K. Kudlicka, R. Brown, A biochemical study on b-glucan synthesis in the cotton fibre, Plant Physiol. 108 (1995), S68.

[109] D. Verma, Z. Hong, Plant callose synthase complexes, Plant Mol. Biol 47 (2001), 693-701.

[110] F.M. Megli, K. Sabatini, EPR studies of phospholipid bilayers after lipoperoxidation. 1. Inner molecular order and fluidity gradient, Chem Phys Lipids 125 (2003), 161-172.

[111] F.M. Megli, L. Russo, K. Sabatini, Oxidized phospholipids induce phase separation in lipid vesicles, FEBS Lett 579 (2005), 4577-4584.

[112] E. Rojas, H.B. Pollard, Membrane capacity measurements suggest a calcium-dependent insertion of synexin into phosphatidylserine bilayers, FEBS Lett 217 (1987), 25-31.

[113] A. Burger, D. Voges, P. Demange, C.R. Perez, R. Huber, R. Berendes, Structural and electrophysiological analysis of annexin $\mathrm{V}$ mutants. Mutagenesis of human annexin $\mathrm{V}$, an in vitro voltage-gated calcium channel, provides information about the structural features of the ion pathway, the voltage sensor and the ion selectivity, J Mol Biol 237 (1994), 479-499.

[114] E. Rojas, H. Pollard, H. Haigler, C. Parra, A. Burns, Calcium-activated endonexin II forms calcium channels across acidic phospholipid bilayer membranes, J. Biol. Chem. 265 (1990), 21207-21215.

[115] R. Berendes, D. Voges, P. Demange, R. Huber, A. Burger, Structure-function analysis of the ion channel selectivity filter in human annexin V, Science 262 (1993), 427-430.

[116] A. Hofmann, Strukturelle und funktionelle Untersuchungen an Annexinen, PhD Thesis Technische Universität München (1998).

[117] R. Huber, R. Berendes, A. Burger, M. Schneider, A. Karshikov, H. Lücke, J. Römisch, E. Paques, Crystal and molecular structure of human annexin $V$ after refinement. Implications for structure, membrane binding and ion channel formation of the annexin family of proteins, J. Mol. Biol. 223 (1992), 683-704.

[118] A. Karshikoff, R. Berendes, A. Burger, A. Cavalie, H. Lux, R. Huber, Annexin V-membrane interaction: an electrostatic potential study, Eur. Biophys. J. 20 (1992), 337-344.

[119] K. Tönsing, S. Kakorin, E. Neumann, S. Liemann, R. Huber, Annexin V and vesicle 
membrane electroporation, Eur. Biophys. J. 26 (1997), 307-318.

[120] F. Sachs, F. Qin, Gated, ion-selective channels observed with patch pipettes in the absence of membranes: novel properties of a gigaseal, Biophys J 65 (1993), 1101-1107.

[121] A. Hofmann, J. Benz, S. Liemann, R. Huber, Voltage dependent binding of annexin V, annexin VI and annexin VII-core to acidic phospholipid membranes, Biochim Biophys Acta 1330 (1997), 254-264.

[122] C. Smith, D.F. Gibson, J.F. Tait, Transmembrane voltage regulates binding of annexin V and lactadherin to cells with exposed phosphatidylserine, BMC Biochem 10 (2009), 5.

[123] A. Bhatnagar, Electrophysiological Effects of 4-Hydroxynonenal, an Aldehydic Product of Lipid Peroxidation, on Isolated Rat Ventricular Myocytes, Circ. Res. 76 (1995), 293-304.

[124] A.K. McNeil, U. Rescher, V. Gerke, P.L. McNeil, The requirement for annexin A1 in plasma membrane repair, J. Biol. Chem. 281 (2006), 35202-35207.

[125] E.B. Babiychuk, A. Draeger, Regulation of ecto-5"-nucleotidase activity via Ca2+-dependent, annexin 2-mediated membrane rearrangement?, Biochem. Soc. Trans 34 (2006), 374-376.

[126] A. Bouter, C. Gounou, R. Bérat, S. Tan, B. Gallois, T. Granier, B.L. d'Estaintot, E. Pöschl, B. Brachvogel, A.R. Brisson, Annexin-A5 assembled into two-dimensional arrays promotes cell membrane repair, Nat Commun 2 (2011), 270.

[127] M. Craxton, Synaptotagmin gene content of the sequenced genomes, BMC Genomics 5 (2004), 43.

[128] A.L. Schapire, B. Voigt, J. Jasik, A. Rosado, R. Lopez-Cobollo, D. Menzel, J. Salinas, S. Mancuso, V. Valpuesta, F. Baluska et al., Arabidopsis synaptotagmin 1 is required for the maintenance of plasma membrane integrity and cell viability, Plant Cell 20 (2008), 3374-3388. [129] A.L. Schapire, V. Valpuesta, M.A. Botella, Plasma membrane repair in plants, Trends Plant Sci 14 (2009), 645-652.

[130] A. Draeger, K. Monastyrskaya, E.B. Babiychuk, Plasma membrane repair and cellular damage control: the annexin survival kit, Biochem Pharmacol 81 (2011), 703-712.

[131] T. Yamazaki, Y. Kawamura, A. Minami, M. Uemura, Calcium-dependent freezing tolerance in Arabidopsis involves membrane resealing via synaptotagmin SYT1, Plant Cell 20 (2008), 3389-3404.

[132] A. Minami, M. Fujiwara, A. Furuto, Y. Fukao, T. Yamashita, M. Kamo, Y. Kawamura, M. Uemura, Alterations in detergent-resistant plasma membrane microdomains in Arabidopsis thaliana during cold acclimation, Plant Cell Physiol. 50 (2009), 341-359.

[133] G. Breton, A. Vazquez-Tello, J. Danyluk, F. Sarhan, Two novel intrinsic annexins accumulate in wheat membranes in response to low temperature, Plant Cell Physiol. 41 (2000), 177-184. [134] M.O. Winfield, C. Lu, I.D. Wilson, J.A. Coghill, K.J. Edwards, Plant responses to cold: Transcriptome analysis of wheat, Plant Biotechnol J 8 (2010), 749-771.

[135] C. Grozinger, S. Schreiber, Regulation of histone deacetylase 4 and 5 and transcriptional activity by 14-3-3-dependent cellular localization, Proc. Natl. Acad. Sci. USA 97 (2000), 7835-7840.

[136] T. Greco, F. Yu, A. Guise, I. Cristea, Nuclear import of histone deacetylase 5 by requisite nuclear localization signal phosphorylation, Mol. Cell. Proteomics 10 (2011), M110.004317. [137] H. Seimiya, H. Sawada, Y. Muramatsu, M. Shimizu, K. Ohko, K. Yamane, T. Tsuruo, Involvement of 14-3-3 proteins in nuclear localization of telomerase, EMBO J. 19 (2000), 2652-2661.

[138] D. Chevalier, E. Morris, J. Walker, 14-3-3 and FHA domains mediate phosphoprotein interactions, Ann. Rev. Plant Biol. 60 (2009), 67-91.

[139] G.S. Athwal, J.L. Huber, S.C. Huber, Phosphorylated nitrate reductase and 14-3-3 proteins. Site of interaction, effects of ions, and evidence for an amp-binding site on 14-3-3 proteins, Plant Physiol 118 (1998), 1041-1048.

[140] T. Jahn, A.T. Fuglsang, A. Olsson, I.M. Brüntrup, D.B. Collinge, D. Volkmann, M. Sommarin, 
M.G. Palmgren, C. Larsson, The 14-3-3 protein interacts directly with the C-terminal region of the plant plasma membrane H(+)-ATPase, Plant Cell 9 (1997), 1805-1814.

[141] I. Capila, M. Hernaiz, Y. Mo, T. Mealy, B. Campos, J. Dedman, R. Linhardt, B. Seaton, Annexin V-heparin oligosaccharide complex suggests heparan sulfate-mediated assembly on cell surface, Structure 9 (2001), 57-64.

[142] A. Winter, A.M. Yusof, E. Gao, H.L. Yan, A. Hofmann, Biochemical characterization of annexin B1 from Cysticercus cellulosae, FEBS J. 273 (2006), 3238-3247.

[143] P. Durek, R. Schmidt, J. Heazlewood, A. Jones, D. MacLean, A. Nagel, B. Kersten, W. Schulze, PhosPhAt: the Arabidopsis thaliana phosphorylation site database. An update, Nucl. Acids Res. 38 (2010), D828-D834.

[144] M. de la Fuente, S. van Bentem, D. Anrather, I. Dohnal, E. Roitinger, E. Csaszar, J. Joore, J. Buijnink, A. Carreri, C. Forzani et al., Site-specific phosphorylation profiling of Arabidopsis proteins by mass spectrometry and peptide chip analysis, J. Proteome Res. 7 (2008), 2458-2470. [145] B. Hille, Ionic channels of excitable membranes, Sinauer Associates, Sunderland (1992). [146] W. DeLano, The PyMOL Molecular Graphics System, http://www.pymol.org (2002), . [147] K. Bryson, L.J. McGuffin, R.L. Marsden, J.J. Ward, J.S. Sodhi, D.T. Jones, Protein structure prediction servers at University College London, Nucl. Acids Res. 33 (2005), W36-W38. 
Table 1: Verified phosphorylation sites in plant annexins

\begin{tabular}{|c|c|c|c|c|}
\hline Protein & Plant & $\begin{array}{l}\text { Phosphorylation } \\
\text { site }\end{array}$ & Literature & Location \\
\hline $\operatorname{Anx}(A t) 1$ & A. thaliana & Ser-70 & [143] & $\begin{array}{l}\text { convex side, IDE loop } \\
\text { EL(pS)NDFER }\end{array}$ \\
\hline $\begin{array}{l}\operatorname{Anx}(\mathrm{At}) 2, \\
\operatorname{Anx}(\mathrm{Bn})\end{array}$ & $\begin{array}{l}\text { A. } \\
\text { thaliana, } \\
\text { Brassica } \\
\text { napus }\end{array}$ & Thr-81 & [52] & $\begin{array}{l}\text { concave side, link between helices IE } \\
\text { and IIA } \\
\text { AVMLW(pT)LDPPER }\end{array}$ \\
\hline $\operatorname{Anx}(\mathrm{At}) 2$ & A. thaliana & Ser-300 & [144] & $\begin{array}{l}\text { convex side, IVDE loop } \\
\text { D(pT)(pS)GDYEDMLVALLGHGDA }\end{array}$ \\
\hline $\operatorname{Anx}(\mathrm{At}) 3$ & A. thaliana & Tyr-217 & [143] & $\begin{array}{l}\text { concave side, link between helices IIIC } \\
\text { and IIID } \\
\text { N(pY)GVTIDK }\end{array}$ \\
\hline $\operatorname{Anx}(\mathrm{At}) 4$ & A. thaliana & Ser-46 & [143] & $\begin{array}{l}\text { concave side, helix IC } \\
\text { KA(pS)KSFFVEDEER }\end{array}$ \\
\hline $\operatorname{Anx}(\mathrm{At}) 5$ & A. thaliana & unknown & [51] & Not specified \\
\hline $\operatorname{Anx}(\mathrm{At}) 7$ & A. thaliana & Ser-224 & [143] & $\begin{array}{l}\text { convex side, IIIDE loop } \\
\text { ED(pS)ENEYIQLLKAVIK }\end{array}$ \\
\hline
\end{tabular}


Table 2: Comparison of selectivity ratios for annexins and conventional ion channels

\begin{tabular}{llll}
\hline Protein & Ions & Selectivity ratio & Reference \\
\hline BK K(Ca) channel & $\mathrm{Na}^{+} / \mathrm{K}^{+}$ & $<0.01$ & {$[145]$} \\
& $\mathrm{Ca}^{2+} / \mathrm{K}^{+}$ & weakly permeant & {$[145]$} \\
\hline L-type calcium channels & $\mathrm{Cs}^{+} / \mathrm{Ca}^{2+}$ & $2.4 * 10-4$ & {$[145]$} \\
& $\mathrm{Na}^{+} / \mathrm{Ca}^{2+}$ & $8.5 * 10-4$ & {$[145]$} \\
\hline Annexin A7 & $\mathrm{Cs}^{+} / \mathrm{Ca}^{2+}$ & 1.05 & {$[114]$} \\
& $\mathrm{Na}^{+} / \mathrm{Ca}^{2+}$ & 0.27 & {$[114]$} \\
\hline Anx $(\mathrm{Zm}) 33 / 35$ & $\mathrm{~K}^{+} / \mathrm{Ca}^{2+}$ & 2.78 & {$[16]$} \\
\hline
\end{tabular}




\section{Figure Legends}

\section{Figure 1}

The fold of annexins, illustrated using the calcium-bound structure of annexin Gh1 from cotton (PDB accession number 3brx). The colouring scheme highlights the N-terminal domain (dark blue), repeat I (light blue), repeat II (green), linker (grey), repeat III (yellow) and repeat IV (red). Calcium ions bound on module I/IV are shown as orange spheres. The $S_{3}$ cluster consisting of Met-112, Cys-116 and Cys-243 is indicated by the location of the residue side chains (shown as sticks). The figure shows a view of the protein front face on (left) and onto the convex membrane binding surface (right). The figure was prepared with PyMOL [146].

\section{Figure 2}

Alignment of Arabidopsis annexins and mapping of predicted and verified phosphorylation sites, as well as 14-3-3 interaction motifs.

Theoretically predicted phosphorylation sites (NetPhos 2.0 score higher than 0.9) are highlighted gray. Experimentally verified phospho-peptides are highlighted blue with the phosphorylated residue in bold. Underlined are 14-3-3 interaction motifs as predicted with the Eucaryotic Linear Motif resource for Functional Sites in Proteins (ELM; http://elm.eu.org/).

The approximate location of the helices of the annexin fold are indicated.

\section{Figure 3}

Top: Alignment of the conserved peptide in 14-3-3 proteins and annexins from A. thaliana. Amino acid residues of high conservation are shown in green, and those of medium conservation in blue. The bold residues indicate a confirmed phosphorylation site. Gene accession numbers are given in the second column.

Bottom: Mapping of the conserved in peptides on the three-dimensional structures of 14-3-3-like protein C from Nicotiana tabacum (left), and annexin 24(Ca32) from Capsicum annuum (right). The aligned peptides from the top panel are highlighted in orange. PDB accession numbers: 109c and 1dk5; figure prepared with PyMOL [146].

\section{Figure 4}

Alignment of the N-terminal regions of Arabidopsis and Oryza annexins. Secondary structure elements were predicted with PSIPRED [147] and are highlighted: green (alpha-helix), red (betastrand). 


\section{Figures}

Figure 1
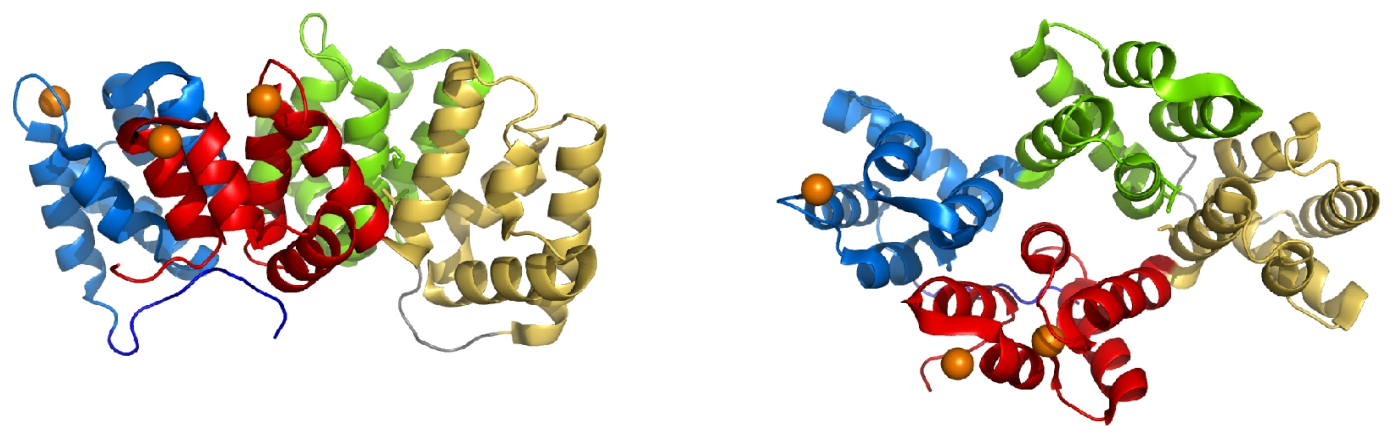


\section{Figure 2}

AnnAt 1

AnnAt2

AnnAt 3

AnnAt 4

AnnAt 5

AnnAt 6

AnnAt 7

AnnAt 8

AnnAt 1 AnnAt2

AnnAt 3 AnnAt 4 AnnAt 5 AnnAt 6 AnnAt 7 AnnAt 8

AnnAt 1 AnnAt2 AnnAt 3 AnnAt 4 AnnAt 5 AnnAt 6 AnnAt 7 AnnAt 8

AnnAt 1 AnnAt2 AnnAt 3 AnnAt 4 AnnAt 5 AnnAt 6 AnnAt 7 AnnAt 8

AnnAt 1 AnnAt2 AnnAt 3 AnnAt 4 AnnAt 5 AnnAt 6 AnnAt 7 AnnAt 8

AnnAt 1 AnnAt2 AnnAt 3 AnnAt 4 AnnAt 5 AnnAt 6 AnnAt 7 AnnAt 8

$$
|---I A----| \quad|--I B---| \quad|-----I C------|
$$

MATLKVSD $\underline{\underline{T} V P A P} \underline{\mathrm{S} D D A E Q L R T A F E G W G T N E D L I}$ IS I LAHRSAEQRKVIRQAYHETYGED MAS LKVPSNVPLPEDDAEQLHKAFSGWGTNEKLI IS I LAHRNAAQRSLIRSVYAATYNED MATIRVPNEVP $\underline{\underline{S} P A Q D S E T L K Q A ~ I R G W G T D E K A I ~ I ~ R V L G Q R D Q S S Q R R K I R E ~} \underline{S} F R E I Y G K D$ ------MALPLELESLTEA I SAGMGMGVDENAL ISTLGKS $\underline{\underline{S}}$ KEHRKLFRKASKSFFVED MATMKI PMTVP $\underline{S} P R V D A D Q L F K A F K G R G C D T S V I I N I L A H R N A T Q R A L I E Q E Y E T K F S D D$ MASLKI PANI PLPEEDSEQLHKAFKGWGTNEGMI I S I LAHRNATQRSF I RAVYAANYNKD MASLKVPATVPLPEEDAEQLYKAFKGWGTNERMI I S I LAHRNATQRSFIRAVYAANYNKD MATIVSP PHF $\underline{\underline{S}-P V E D A E N I K A A C Q G W G T N E N A I ~ I S ~ I ~ L G H R N L F Q R K L I R Q A Y Q E ~ I Y H E D ~}$

60

60

60

53

60

60

60

59

---------LLKTLDKELSNDFERA ILLWTLEPGERDALLAN-----EATKRWTSSNQ 104 ---------LLKALDKELS S SFERAVMLWTLDPPERDAYLAK-----ESTKMFTKNNW 104 ----------LIDVLSSELSGDFMKAVVSWTYDPAERDARLVNKILNKEKKKKSLLENLK 109 EERAFEKCHDHFVRHLKLEFS-RFNTAVVMWAMHPWERDARLVK-----KALKKGEEAYN 107 ---------LRKRLH $\underline{\underline{S} E L H G H L K K A V L L W M P E A V E R D A S I L K-----R \underline{S} L R G A V T D H K} 104$ ---------LLKELDGELSGDFERVVMLWTLDPTERDAYLAN-----ESTKLFTKNIW 104 ---------LLKELDRELS $\underline{S}$ GDFERAVMLWTFEPAERDAYLAK-----ESTKMFTKNNW 104 ---------LIHQLKSELSGNFERAICLWVLDPPERDALLAN-----LALQKPIPDYK 103

- IIB--- | |-----IIC----- | |--IID-- | |---IIE---- |

VLMEVACTRTSTQLLHARQAYHARYKKSLEEDVAHHTTGDFRKLLVSLVTSYRYEG--DE 162 VLVEIACTRPALELIKVKQAYQARYKKSIEEDVAQHTSGDLRKLLLPLVSTFRYEG--DD 162 VIVEISCTTSPNHLIAVRKAYCSLLFDSSLEEHIASSLPFPLAKLLVTLASTFRYDK--DR 167 LIVEVSCTRSAEDLLGARKAYH $\underline{\underline{S}} L F$ DQ $\underline{S} M E E D I A S H V H G P Q R K L L V G L V S A Y R Y E G--N K 165$ AIAEIICTRSGSQLRQIKQVYSNTFGVKLEEDIESEASGNHKRVLLAYLNTTRYEG--PE 162 VLVEIACTRP SLEFFKTKQAYHVRYKTSLEEDVAYHTSGNIRKLLVPLVSTFRYDGNADE 164 VLVEIACTRSALELFNAKQAYQARYKTSLEEDVAYHTSGDIRKLLVPLVSTFRYDG--DE 162 VLVEIACMRSPEDMLAARRAYRCLYKHSLEEDLASRTIGDIRRLLVAMVSAYKYDG--EE 161

|-------IIIA-------| |-IIIB--| |---IIIC----| |--IIIDVNMTLAKQEAKLVHEKIK---DKHYNDEDVIRILSTRSKAQINATFNRYQDDHGEEILKS 219 VNMMLARSEAKILHEKVS $---E \underline{K}$ SYSDDDFIRILTTRSKAQLGATLNHYNNEYGNAINKN 219 TDAEVATIEAAMLREAIE---KKQLDHDHVLYILGTRS IYQLRETFVAYKKNYGVTIDKD 224 VKDDSAKSDAKILAEAVA $\underline{\underline{S} S G E A A V K D E V V R I L T T R S K L H L Q H L Y K H F N E I K G S D L L G G ~} 225$ IDNA $\underline{\underline{S} V E N D A R T L K S A V A R--K H K S D D Q T L I Q I F T D R S R T H L V A V R S T Y R S M Y G K E L G K A ~} 220$ VNVKLARSEAKTLHKKIT---EKAYTDEDLIRILTTRSKAQINATLNHFKDKFGSSINKF 221 VNMTLARSEAKILHEKIK---EKAY YDDDLIRILTTRSKAQISATLNHYKNNFGTSMSKY 219 IDEMLAQSEAAILHDEIL---GKAVDHEETIRVLSTRSSMQLSAIFNRYKDIYGTSITKD 218

| |----IIIE-----| |---IVA-----| |---IVB--- |

LEEGDDDDKFLALLRSTIQCLTRPELYFVDVLRSAINKTG--TDEGALTRIVTTRAEI-- 275 LKEESDDNDYMKLLRAVITCLTYPEKHFEKVLRLS INKMG--TDEWGLTRVVTTRTEV-- 275 VDGCPGDADLRSLLKVAIFCIDTPEKHFAKVVRDS IEGFG--TDEDSLLTRAIVTRAEI-- 280 VS------KSSLLNEALICLLKPALYFSKILDA SLNKDADKTTKKWLTRVFVTRADHSD 278 IRDETRG-NFEHVLLTILQCAENSCFYFAKALRKSMKGLG--TDDTALIRIVVTRAEV-- 275 LKEDSND-DYYVQLLKTAIKCLTYPEKYFEKVLRRAINRMG--TDEWALTRVVTTRAEV-- 276 LKEDSEN-EYYIQLLKAVIKCLTYPEKYFEKVLRQAINKLG--TDEWGLTRVVTTRAEF-- 274 LLNHPTN-EYLSALRAAIRCIKNPTRYYAKVLRNS INTVG--TDEDALNRVIVTRAEK-- 273

$$
|---I V C----| \quad|-I V D--| \quad|--I V E---|
$$

DLKVIGEEYQRRNSIPLEKAITKDTRGDYEKMLVALLGEDDA- 
Figure 3

\begin{tabular}{|c|c|}
\hline GRF1 (14-3-3) & At $4 g 0900 \odot$ \\
\hline GRF2 (14-3-3) & At $1 \mathrm{~g} 78300$ \\
\hline GRF3 (14-3-3) & At5g38480 \\
\hline GRF5 (14-3-3) & At5g16050 \\
\hline GRF8 (14-3-3) & At5g6543c \\
\hline GRF9 (14-3-3) & At $2 g 4259$ \\
\hline GRF10 (14-3-3) & At1g2230 \\
\hline GRF11 (14-3-3) & At1g3476 \\
\hline GRF12 (14-3-3) & At1g2648 \\
\hline GRF13 (14-3-3) & At1g7822 \\
\hline GF14PHI (14-3-3) & At1g3516 \\
\hline GRF15 (14-3-3) & At5g1045c \\
\hline$A n \times(A t) 1$ & At1g3572 \\
\hline$A n \times(A t) 2$ & At5g6502 \\
\hline$A n \times(A t) 3$ & At $2 g 3876$ \\
\hline$A n \times(A t) 4$ & At $2 \mathrm{~g} 3875$ \\
\hline$A n \times(A t) 5$ & At1g6809 \\
\hline$A n \times(A t) 6$ & At5g1022 \\
\hline $\operatorname{An} \times(A t) 7$ & At5g1023 \\
\hline$A n x(A t) 8$ & At5g123 \\
\hline
\end{tabular}

KGDYHRYLAEFKSGQER KGDYHRYLAEFKTGQER KGDYHRYLAEFKAGAER KGDYHRYLAEFKTGAER KGDYHRYLAEFKSGDER KGDYYRYLAEFKSGNER KGDYYRYLAEFSSGAER KGDYFRYLAEFKSGADR KGDYYRYLAEFKTEQER KGDYFRYMAEFGSDAER KGDYHRYLAEFKTGQER KGDYHRYMAEFKSGDER-

RGDYEKMLVALLGEDDASGDYEDMLVALLGHGDA SGDYKDFIITLLGS - - KI KGNYRDFLLTLLSKSD - TSHYRTFLLSLLGPNV - SGDYKDMLLALLGHDHAHGDYEDILLALLGHDHASGDYKAFLLALLGHGKQL
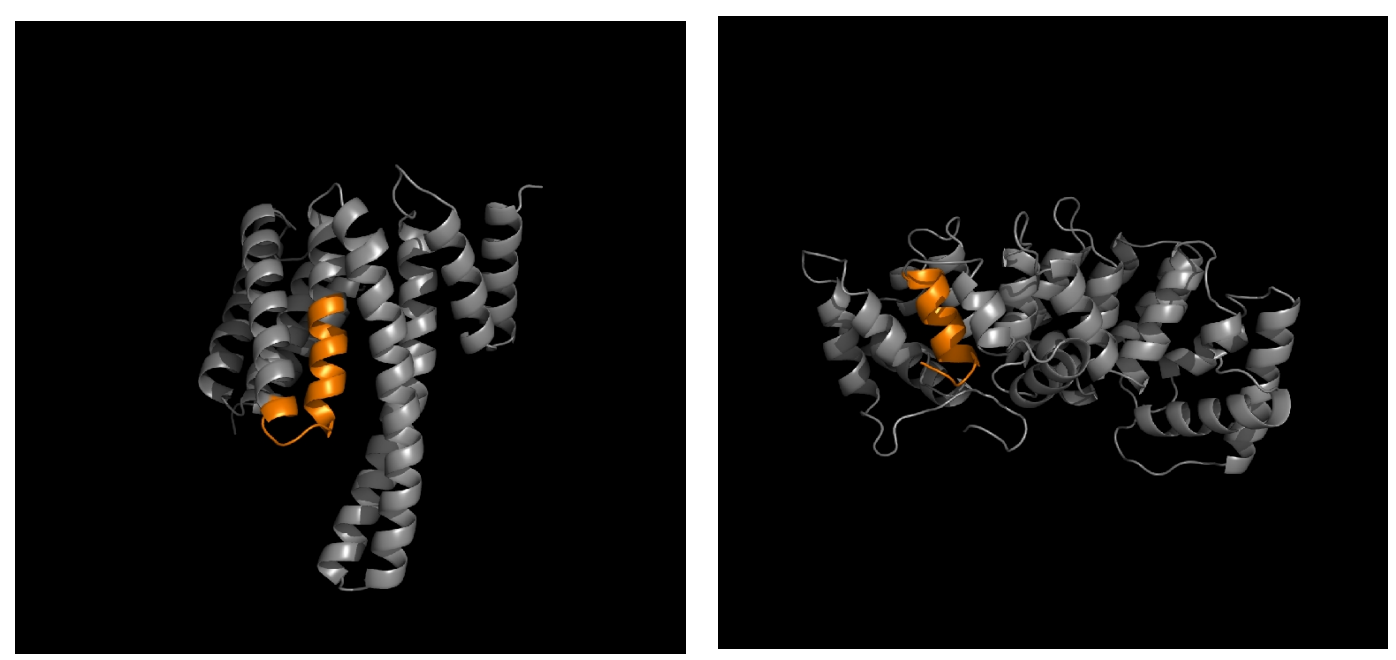


\section{Figure 4}

\begin{tabular}{|c|c|}
\hline t2 & (1) \\
\hline & --MATIRVPNEVPSPAQDSETLKRAIR- \\
\hline & 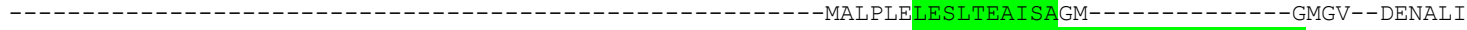 \\
\hline & 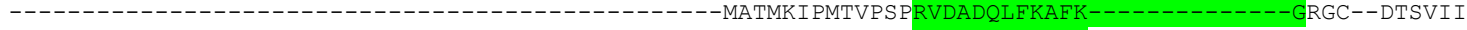 \\
\hline & 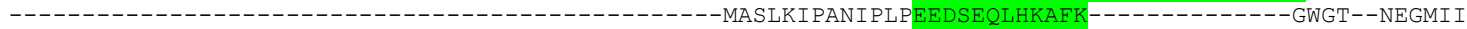 \\
\hline & 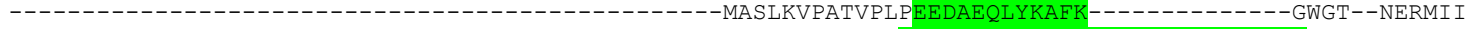 \\
\hline & 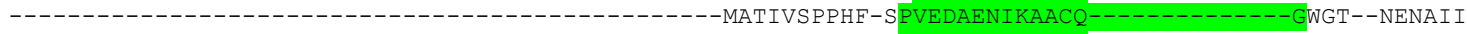 \\
\hline 70 & ---------- \\
\hline 50 & 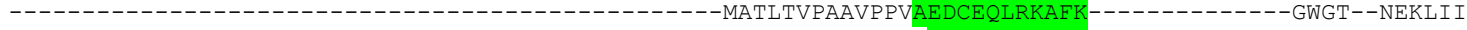 \\
\hline & 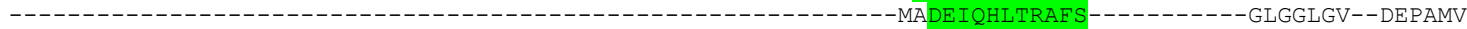 \\
\hline & LLFLHFSPHSLSSSAASAGGGEAAAAAA \\
\hline & 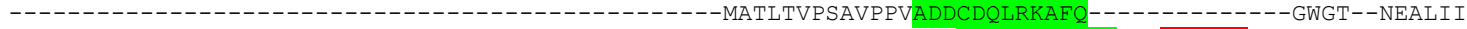 \\
\hline 50 & 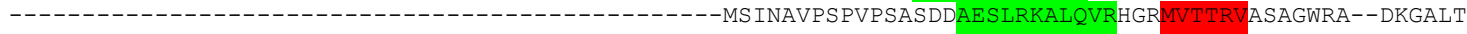 \\
\hline 70 & - \\
\hline & ADCRHLNQF \\
\hline
\end{tabular}

